\title{
Representações discursivas da Veja e Carta Capital sobre o rompimento da barragem da Samarco: crime e desastre
}

\author{
The anatomy of a corporate crime in the discourse of Veja and Carta Capital on \\ the breaking of the Samarco dam
}

\author{
Carlos Henrique Gonçalves Freitas ${ }^{1}$ \\ Fernanda Junia Dornela ${ }^{2}$ \\ Maizy Cassia Silva ${ }^{3}$ \\ Valdir Machado Valadão Júnior ${ }^{4}$ \\ Cintia Rodrigues de O Medeiros ${ }^{5}$
}

\begin{abstract}
Resumo
Este estudo tem como objetivo analisar as representações discursivas do crime corporativo ambiental cometido pela Samarco, em Bento Rodrigues, em 2015, nas reportagens de duas revistas de circulação nacional, a Veja e a Carta Capital, veiculadas durante o primeiro ano após o ocorrido. As corporações contemporâneas têm orientado suas estratégias discursivas pela responsabilidade social corporativa, no entanto, crimes e ilegalidades no âmbito das corporações têm ganhado cada vez maior notoriedade na mídia, revelando uma distância significativa entre a prática e o discurso. A forma com que esses fenômenos são reportados pela mídia traz implicações na compreensão da sociedade acerca do ocorrido. Utilizou-se a técnica análise de discurso, considerando os elementos presentes na construção do discurso: hegemonia, contradição, reconhecimento, intertextualidade e representação. Os resultados apontam que as representações de ambas as revistas sobre o crime corporativo são similares: a empresa é vítima, a empresa é culpada, o rompimento da barragem é um crime corporativo.
\end{abstract}

Palavras-chave: Crime corporativo. Responsabilidade Social Corporativa. Samarco. Representações Discursivas. Corporações.

\begin{abstract}
This study aims to analyze the discursive representations of environmental corporate crime committed by Samarco, in Bento Rodrigues, in 2015, in the reports of two national magazines, Veja and Carta Capital, published during the first year after that. Contemporary corporations have oriented their discursive strategies towards corporate social responsibility, however, crimes and illegalities within corporations have gained increasing media attention, revealing a significant distance between practice and discourse. The way in which these phenomena are reported in the media has implications for society's understanding of what has occurred. The discourse analysis technique was used, considering the elements present in the discourse construction: hegemony, contradiction, recognition, intertextuality and representation. The results point out that the representations of both magazines on corporate crime are similar: the company is a victim, the company is guilty, the breach of the dam is a corporate crime.
\end{abstract}

Keywords: Corporate crime. Corporate social responsibility. Samarco. Discursive Representations. Corporations.

Mestrado, com Distinção, em Applied English Language Studies (Cardiff University, 1993). Brasil. Afiliação: Universidade Federal de Uberlândia. Lattes: http://lattes.cnpq.br/4183200831193982. Email: http://lattes.cnpq.br/4183200831193982

2 Mestre em Administração pelo Programa de Pós-Graduação em Administração da Universidade Federal de Uberlândia (UFU), na linha de pesquisa Organização e Mudança. Brasil. Afiliação: Universidade Federal de Uberlândia. Lattes: http://lattes.cnpq.br/4381578569014054. Email: fernandadornela.ufv@gmail.com

3 Mestranda em Administração no Programa de Pós-graduação Acadêmica da Universidade Federal de Uberlândia. Brasil. Afiliação: Universidade Federal de Uberlândia. Lattes: http://lattes.cnpq.br/2142831703084207. Email: maizycassia@hotmail.com

4 Doutorado em Engenharia de Produção pela Universidade Federal de Santa Catarina (2003). Professor Associado da Universidade Federal de Uberlândia. Brasil. Afiliação: Universidade Federal de Uberlândia. Lattes: http://lattes.cnpq.br/1901493718203318. Email: valdirjß@ufu.br

5 Doutora em Administração pela Fundação Getulio Vargas - EAESP - linha de pesquisa Estudos Organizacionais. Brasil. Afiliação: Universidade Federal de Uberlândia. Lattes: http://lattes.cnpq.br/8358316505475749. Email: cintia@ufu.br 


\section{Introdução}

A atuação contemporânea das corporações é objeto de atenção por parte dos noticiários jornalísticos e em revistas semanais, o que contribui para a construção de significados sobre o que elas fazem e como elas fazem. Quando as condutas corporativas resultam em danos à sociedade, como nos casos de crimes ambientais, as revistas semanais destinam espaços para expor textos e imagens sobre esses, tornandose lugares centrais de produção e circulação de representações discursivas sobre o que tenha ocorrido.

No contexto de condutas corporativas que causam prejuízos, um caso a ser considerado para análise ocorreu no subdistrito de Bento Rodrigues, Minas Gerais, Brasil, em 5 de novembro de 2015, envolvendo a empresa Samarco - controlada em partes iguais por dois acionistas: a BHP Billiton Brasil Ltda. e Vale S.A (SAMARCO, 2014). O crime ocorrido no vilarejo, que abrigava cerca de 600 habitantes (GONÇALVES et al, 2015), envolveu o rompimento da barragem de rejeitos de Fundão, pertencente à empresa.

Nas Ciências Jurídicas, o crime pode ser definido sob três perspectivas conceituais: material, formal ou analítica, segundo propósitos específicos. Neste texto, focaremos no conceito material de crime, para o qual a essência da intenção ou das consequências de dado comportamento, positivo ou omissivo, caracteriza o delito, visto que ele representa uma ameaça, desrespeito ou prejuízo a bens sociais e jurídicos, que podem estar circunscritos a direitos e garantias, individuais ou coletivas (ESTEFAM; GONÇALVES, 2012; DELMANTO, 2000; MIRABETE, 2000). Essa abordagem permite destacar que a ação de qualquer pessoa constituída perante o direito, seja ela natural ou jurídica, com capacidade jurídica reconhecida na norma, está sujeita a responder por seus atos, conforme a lei (DINIZ, 2012). Destarte, a capacidade jurídica, ou a possibilidade de responsabilização por atos ou omissões delituosos, na forma da lei, se aplica a indivíduos e empresas, visto que tal comportamento constitue um risco ou prejuízo juridicamente reconhecido.

Nos estudos organizacionais, os crimes corporativos podem ser definidos como decisões e atos corporativos que resultam em prejuízos para a sociedade, sejam consumidores, empregados, comunidades, investidores, governos ou o meio ambiente (MACHADO, 1987), i.e. os stakeholders que, direta ou indiretamente, têm interesses nas atividades da firma ou por ela são afetados - sendo tal relação variável segundo a percepção da sociedade sobre o papel das firmas (MAGILL; QUINZII; ROCHET, 2015). Complementarmente, esse tema ganhou evidência nos estudos organizacionais a partir dos anos 1970, pois escândalos envolvendo organizações - como o da Union Carbide, em Bhopal, na Índia, em 1984; o da Enron, nos EUA, em 2001; o da Petrobras, no Brasil, desde 2014; o da Zara, em São Paulo, em 2011; o da Deepwater Horizon, envolvendo a BP, no Golfo do México, em 2010; etc. - não cessam de ocorrer e ainda é complexa sua compreensão. Além disso, de modo geral, nos estudos de Administração, pouco se discutem seus aspectos negativos, que parecem não fazer parte do contexto organizacional relacionados a esses escândalos (OLIVEIRA, 2013).

Mesmo a doutrina e a jurisprudência do Direito pátrio têm reconhecido, a partir da crescente importância dos crimes ambientais, coincidentemente com o tema deste trabalho, a imputabilidade da pessoa jurídica no direito penal. Assim, a corporação, antes afastada de responsabilização penal, vê-se diante da efetiva possibilidade de ter que responder por seus atos diretamente (ESTEFAM; GONÇALVES, 2012; e BRASIL, STF, 2014).

Inexoravelmente, tais crimes reverberam na mídia em geral (BORGES et al., 2016) e os discursos de suas notícias evidenciam a construção de representações de mundo ou versões da realidade, conforme determinados propósitos, bem como identidades sociais e percepções de valores caros a seus sujeitos, uma vez que os textos são organizados, produzidos e transformados em um processo de construção ideológica (FAIRCLOUGH, 1993). Assim, as notícias sobre as corporações produzem sentido sobre o que elas são, o que fazem e como fazem, entre outros aspectos. Por sua vez, esses sentidos servem de fragmento para a composição de outros discursos, que são adicionados a outros já existentes, reproduzindo e transformando representações sociais, crenças e valores sobre as mesmas corporações e seu contexto socioeconômico e cultural (OLIVEIRA; VALADÃO JUNIOR; MIRANDA, 2013).

Diante desse contexto, este estudo tem como objetivo analisar as representações discursivas do crime corporativo ambiental cometido pela Samarco, em Bento Rodrigues, em 2015, nas reportagens de duas revistas de circulação nacional, a Veja e a Carta Capital, veiculadas um ano após o ocorrido. A abordagem 
da pesquisa é interpretativista e utiliza-se a análise de discurso para interpretar o material empírico. O corpus de pesquisa foi composto por 13 reportagens sobre o crime, considerando o período do primeiro ano após o ocorrido, sendo 8 veiculadas na Carta Capital e 5 na Revista Veja.

A estrutura do artigo tem cinco seções, contando com esta introdução. Na segunda seção, discutimos as relações entre sociedade e corporações, e os conceitos sobre crime e crime corporativo. Em seguida, apresentamos os procedimentos de pesquisa, os resultados e discussão. Na quinta e última seção apresentamos nossas considerações finais.

\section{As relações entre corporações e sociedade: sustentabilidade, governança \& responsabilidade social}

Da mesma forma que a relação entre lei e valores sociais se impõe, a relação entre o desempenho econômico da empresa e seu desempenho social também é um critério de validação do comportamento das corporações, visto que essa relação contém construtos de importância reconhecida, como governança corporativa (GC), responsabilidade social corporativa (RSC) e sustentabilidade, e que as práticas relacionadas a esses construtos podem ter um efeito benéfico sobre o desempenho financeiro da empresa. Assim, argumenta-se, a seguir, que seja essencial à organização harmonizar seus interesses, os de seus diversos stakeholders e o contexto em que opera, por conta de potenciais conflitos entre sua natureza econômica e a lógica capitalista do lucro, assim como entre sua natureza social e a lógica do bem comum, norteadora do Estado de direito em que a organização opera.

O termo sustentabilidade surgiu na Biologia e na Ecologia, representando a capacidade de um ecossistema em manter um equilíbrio dinâmico que possibilite a permanência da maior biodiversidade possível (BOFF, 2010). Entretanto a utilização indiscriminada e acrítica do termo, ao longo dos anos, resultou em um afastamento crescente dessa definição original (DA SILVA; REIS; AMÂNCIO, 2014). A sustentabilidade está cada vez mais presente no contexto organizacional (CLARO; CLARO; AMÂNCIO, 2008), passando a associar-se à capacidade da organização se autossuntentar e se automanter (PHILIPPI, 2001).

Sustentabilidade é também associada ao desenvolvimento sustentável, isto é, refere-se também às necessidades da atual geração, sem comprometer as necessidades das gerações futuras (DA SILVA; REIS, 2011). Porém essa perspectiva é questionável por não definir quais são as necessidades presentes e futuras (BARBOSA, 2008), dando margem a discussões sobre o construto. A maioria delas reconhece, entretanto, que a sustentabilidade é construída sobre três dimensões inter-relacionadas: a ambiental, a social e a econômica, ou triple bottom line (ELKINGTON, 1997; CLARO; CLARO; AMÂNCIO, 2008; DA SILVA; REIS; AMÂNCIO, 2014).

Essa tridimensionalidade pode ser estendida a um paradigma estrutural radical, com base no conflito, em que a questão da equidade - no acesso e preservação de recursos, na distribuição de riqueza, na ocupação de territórios e na participação no fenômeno cultural - é central (HALPERN et al, 2013; SACHS, 1994). Logo, uma empresa sustentável é aquela que opera sem esgotar sua capacidade de continuidade, em longo prazo, apesar dos imprevistos que possam ocorrer, respeitando suas fontes de fatores de produção (naturais e sociais), os múltiplos interesses de seus mais variados stakeholders e o equilíbrio de seu contexto ambiental, social e econômico, um bem comum sociopolítico (ALMEIDA, 2002).

A relação entre equidade, equilíbrio sociopolítico e bem comum não é nova, de Aristóteles a John Rawls, mas de especial interesse é a abordagem habermasiana, pois enquanto a política é uma ferramenta de uma deliberação comunicativa entre a sociedade civil, seus agentes econômicos e os operadores da burocracia estatal na esfera pública, a economia ainda representa a principal influência sobre essa esfera. Sob essa ótica, a discussão sobre sustentabilidade envolve trade-offs a serem negociados entre a organização, a sociedade e o Estado (HALPERN, 2013), a partir de múltiplas perspectivas que têm, em comum, a necessidade de se alcançar e preservar certa equidade entre seus membros.

Nesse sentido, o discurso organizacional sobre sustentabilidade - de gestores, empreendedores, ONGs e governo a outros stakeholders, como funcionários, mercado, acionistas, concorrentes, parceiros, eleitores etc. - busca vincular práticas organizacionais ambientais, sociais e econômicas a uma imagem 
positiva da empresa (CLARO; CLARO; AMÂNCIO, 2008). Complementarmente, esse discurso também reflete o reconhecimento de questões legais - a partir de legislação com fulcro no triple bottom line (TBL) -, bem como de demandas de caráter mais geral da sociedade (HENRIQUES; SANT'ANA, 2013).

Os consumidores, atentos aos efeitos do uso indiscriminado de recursos sobre as condições naturais e sociais, tendem a optar por produtos e serviços de empresas que adotam posturas responsáveis com repercussão sobre toda a sociedade (HENRIQUES; SANT'ANA, 2013). Logo, ao adotarem o discurso da sustentabilidade, as organizações estão investindo na tentativa de permanecer no mercado, visto que compor uma "lista suja" pode comprometer sua imagem e acarretar sérias consequências, como dificultar os negócios e a obtenção de certificações de boas práticas (HENRIQUES; SANT'ANA, 2013).

Porém, frequentemente, há um hiato entre o discurso e as práticas das organizações em relação às posturas e responsabilidades intrínsecas a essas dimensões (COSTA; VALDISSER, 2015). Sustentabilidade passou a ser empregada como um elemento de retórica, disfarçando interesses particulares sem relação efetiva com a origem do construto (DA SILVA; REIS; AMÂNCIO, 2014). A efetiva incorporação do TBL nas organizações demanda mudanças na cultura organizacional (BENITES; POLO, 2013). Isto não implica somente a elaboração de políticas ou a formalização de processos, mas também reais alterações nas formas de atuação e tomadas de decisões da organização, bem como em suas relações com o mercado e a comunidade em que atua.

Entender o discurso organizacional é desnudar aquilo que as empresas desejam que seja difundido na sociedade (BORCHARDT; SIENA, 2014). As organizações veem no discurso uma estratégia capaz de influenciar a maneira de pensar e agir da sociedade sobre determinado assunto, constituindo um instrumento propagandístico e, muitas vezes, falso e banalizado (COELHO; COELHO; GODOI, 2013).

Assim, o apelo à RSC decorre da extensão do papel da organização para além da perspectiva econômica, bem como de pressões práticas que exerce sobre a firma. À medida que a sociedade se conscientiza que as atividades econômicas das organizações têm efeitos diversos sobre ela e seu meio, é possível compreender que os interessados na atividade das organizações e os afetados por ela (stakeholders) exerçam pressão sobre os passos da organização. Há evidências de que a pressão de stakeholders - em especial empregados, investidores e clientes - seja um fator determinante na introdução de RSC pelas organizações, inclusive comprovando sua relação positiva com o desempenho (HELMIG; SPRAUL; INGENHOFF, 2016). Nesse cenário, é possível questionar se empregados, investidores e clientes exercem tais pressões nessas capacidades ou como atores sociais mais abrangentes.

Dando continuidade à argumentação, é comum atribuir-se à GC uma natureza disciplinadora, baseada na transparência, na accountability, no empowerment e na teoria da agência. Portanto, envolvendo relações entre perspectivas internas da organização, i.e., da gerência e da alta administração, e externas, i.e., de seus acionistas. A teoria do stakeholder, contudo, implica que a boa governança não se limite apenas às necessidades dos acionistas, quotistas, partes beneficiárias ou outros stakeholders juridicamente mais próximos e interessados nos resultados da firma (seus stakeholders imediatos), na distribuição de dividendos ou em seu valor (ARGANDOÑA, 1998, e MAGILL; QUINZII; ROCHET, 2015).

Diz-se que o objetivo da corporação seja o lucro e que o único uso legítimo de seus recursos seja para maximizá-lo ou remunerar o capital de seus proprietários (FRIEDMAN, 1962), porém essa visão é historicamente limitada e pode levar ao descarte de evidências empíricas recentes (FLANNERY, 2000; WEl; EGRI; LIN, 2014; SILVA et al., 2018). Uma pesquisa do Department of Trade and Industry, do Reino Unido (hoje o Department for International Trade), indicava que 80\% das empresas listadas no FTSE-100 haviam passado a publicar e divulgar informações sobre seu "desempenho ambiental" e seu "impacto social" como reconhecimento aos benefícios que a RSC trazia para aquelas empresas (DONALDSON; FAFALIOU, 2003). Reconhecia-se que a integração de considerações sociais e ambientais, de forma voluntária, por parte das empresas, a seus objetivos econômicos, efetivamente contribuía para seu desempenho na bolsa.

Enquanto a sustentabilidade pode ser desdobrada na TBL (SLAPER; HALL, 2011), a RSC poderia ser compreendida como uma pirâmide com seus lados representando as perspectivas da legalidade, economia, ética e filantropia. Partindo dessas perspectivas, a empresa buscaria orientar seus esforços de RSC conforme seus objetivos de promoção de causas sociais e filantropia; de ações de marketing, relacionadas 
a causas com reflexos nos negócios da organização; e de marketing social corporativo, isto é, de mudanças comportamentais e de práticas empresariais responsáveis (CARROLL, 2008; e KOTLER; LEE, 2005). Assim, hoje, é possível definir RSC como o conjunto de obrigações das organizações com o avanço do ambiente social, cujos benefícios são múltiplos na promoção de interesses igualmente diversificados, envolvidos ou afetados pelas atividades e pelo desempenho da organização (MACHADO FILHO, 2002).

Da mesma forma, como os stakeholders imediatos são afetados pelo desempenho social da firma, outros stakeholders sem relação direta com a firma podem ser indiretamente afetados por fatos, contábeis ou não, em que a firma seja parte ou que tenha peso em seu desempenho social, em especial em longo prazo (BESSIRE, 2010). Há, assim, uma interdependência entre os desempenhos econômico e social e os stakeholders imediatos e estendidos (NTIM; SOOBAROYEN, 2013). Abordagens utilitaristas (BESSIRE, op. cit.) sobre os desafios da organização comprometem tanto a relação entre acionistas, alta administração e direção executiva como a coerência entre os objetivos, metas, missão e visão da firma e o TBL da sustentabilidade, os pilares da GC e a pirâmide da RSC (SLAPPER; HALL, 2011) em longo prazo. Os objetivos estratégicos da firma não podem ignorar o contexto social em que ela opera, nem as repercussões de suas atividades sobre ele.

Assim, é natural que a relação entre GC e RSC leve também em consideração o espaço de gestão que a firma tem para se ajustar a riscos que surjam em seu contexto ou ambiente de negócios, de forma a reforçar sua continuidade - sejam processos de controladoria, sejam de planejamento estratégico, sejam de interação ambiental, sejam de boa gestão, pura e simples. Mesmo que de uma perspectiva funcionalista, a GC e a RSC estão relacionadas ao reconhecimento de que a empresa também atende a interesses aparentemente alheios, mas legitimamente estabelecidos na sociedade e no ambiente em que ela opera, que indiretamente favorecem seu desempenho e sua continuidade em longo prazo (HELMIG; SPRAUL; INGENHOFF, 2016).

Há muita confusão entre GC e RSC (AMARANTE et al, 2015), porém a melhor forma de percebê-las é como complementares. Enquanto algumas pesquisas apontam na direção de uma relação positiva entre os dois construtos e os resultados da firma e seu valor, outras indicam o contrário. Não obstante, há uma prevalência da corrente que defende a existência de uma relação positiva e efetiva entre o desempenho social corporativo, a capacidade de resposta social da organização, a gestão de questões sociais relacionadas a seu ambiente e atividades, e o desempenho econômico. Por exemplo, Elkinton (2006) defende que o TBL da sustentabilidade tem um papel aglutinador com a CG e a RSC, sendo as ações inspiradas por esses três construtos convergentes e com impacto sobre a organização. Além disso, esse impacto seria maximizado por um entendimento mais amplo de stakeholder (i.e., todas as partes interessadas e afetadas pelas atividades da firma) e sem limitar a relação entre GC, RSC e sustentabilidade a ideias imediatas de transparência, honestidade ou prestação de contas.

Argumenta-se que, quanto maior a proporção de stakeholders externos envolvidos em decisões com impacto social, melhor será o desempenho social corporativo, pois a legitimidade externa de suas ações será também maior. Destaca-se, ainda, que a GC, como via de transparência, permite à organização maximizar sua RSC e agir de forma oportuna (AMARANTE et al, 2016). Confirmando a relação entre GC, RSC e desempenho, Ntim e Soobaroyen (2013) evidenciam que há uma relação positiva entre GC e RSC e que suas práticas, se coordenadas, têm um efeito benéfico sobre as finanças da empresa. Amarante (op. cit.) ainda ressalta a importância, no planejamento estratégico e nas políticas de GC e RSC, de se considerar as características institucionais da firma, de suas operações e de seu ambiente.

Elementos externos à empresa e à perspectiva econômica trazem ao debate a ideia do bem comum, do qual nem a empresa privada pode se isentar. O limite do caráter social das empresas (fundadas sobre um instrumento legal, o contrato social que as vincula à sociedade) deve ser traçado de forma a respeitar garantias e direitos, jurídica e socialmente estabelecidos, que são a expressão de sua identidade jurídica e civil no Estado de direito (VARELA, 2012). A empresa tem compromissos sociais na medida da lei e de normas sociais subtendidas no contrato social que fundou o Estado, não obstante seus interesses específicos. GC, RSC e Sustentabilidade são conceitos abstratos, mas com efeitos concretos sobre a vida da empresa e da sociedade, sendo medidas da intersubjetividade entre a pessoa jurídica e seus stakeholders, juridicamente 
reconhecidos ou não. Seus alcances imediatos podem estar previstos legalmente e serem sujeitos a questionamentos na instância jurídica, mas seus efetivos alcances também são dados pelas relações de poder entre atores socioeconômicos e políticos.

\section{Crime e crime corporativo}

Materialmente, o crime é caracterizado pela essência do fenômeno. Assim, ele constitui um comportamento que viola um bem jurídico protegido e que tem relevância frente à sociedade. Formalmente, o foco recai sobre a forma da sanção cominada ao crime, sendo, então, necessário que a ação ou omissão, que constitua uma transgressão à lei penal, por dolo ou culpa, esteja igualmente tipificada na norma jurídica. Por fim, analiticamente, o crime é definido prevendo-se as estruturas e elementos do crime, organizando-os e interrelacionando-os em um sistema jurídico racional e uniforme. Os conceitos formal e analítico de crime têm como principais destinatários os operadores do Direito, i.e. juízes, promotores e defensores, orientando-os na interpretação do fenômeno jurídico, em sua tipificação e na aplicação da sanção devida ao transgressor. Por outro lado, o conceito material de crime tem por objetivo limitar e orientar o poder do legislador na criminalização de comportamentos (ESTEFAM; GONÇALVES, 2012; DELMANTO, 2000; MIRABETE, 2000), segundo uma ordem legal superior (i.e., a Constituição, KELSEN, 1998).

Este trabalho explora o conceito material de crime, visto que essa conceituação fundamenta a proteção de bens sociais e jurídicos (e.g. direitos e garantias individuais e coletivos, positivados tácita ou implicitamente na norma), que, assim podem ser estendidos, no foro dos estudos organizacionais, a interesses legítimos de grupos específicos, ao bem comum e à teoria do stakeholder, gestados em um processo de reconhecimento e validação de valores sociais além dos interesses da empresa, de seus acionistas e de sua alta administração (ARGANDOÑA, 1998). A norma e o ordenamento jurídico pressupõem elementos caros ao Estado de direito e à república (BOBBIO, 2000). Destarte, as ações das empresas, como as ações das pessoas naturais, devem ser legais, isto é, de acordo com a legislação posta pelo Estado, segundo um processo de representação democrática, e devem ser legítimas, ou seja, de acordo com a fundamentação principiológica da norma positivada, os ideais da sociedade e seu bem comum (TEIXEIRA, 2012).

Condutas ilegais e criminosas trazem graves prejuízos para os diferentes stakeholders sociais, que se encontram fragmentados entre consumidores, trabalhadores, governo, comunidade, meio ambiente, parceiros, acionistas e alta administração. Ainda, esses atos, muitas vezes, são encobertos e terminam esquecidos pela sociedade; bem como há que se considerar a dificuldade em distinguir entre atos criminosos e comportamentos ilícitos e se a responsabilidade é da empresa ou de indivíduos. Nesse contexto difuso, um lado sombrio das organizações encontra fértil terreno e é frequentemente abandonado nos estudos da administração (BORGES; MEDEIROS, 2014; BORGES et al, 2016).

A diferença entre crime corporativo e comportamento corporativo ilegal é que, naquele, as ações são julgadas em tribunais, onde é decido se a empresa cometeu ou não um ato criminal, com penalizações. Já neste, as violações de leis civis e administrativas são resolvidas usualmente com multas e decretos (BAUCUS; DWORKIN, 1991); assim, nem todos os comportamentos corporativos ilegais são criminosos.

A controvérsia na determinação de um crime corporativo é central no debate sobre o tema. De um lado, estão os defensores do conceito estritamente legalista de crime corporativo (BAUCUS; DWORKIN, 1991). Do outro, estão aqueles que defendem que as definições do Estado para o que seja crime devam ser substituídas por aquelas que levem em conta os direitos humanos, individuais e coletivos (MICHALOWSKI; KRAMER,1987; PEARCE; TOMBS, 1999). Isto porque as corporações têm poder para influenciar a elaboração e aplicação de leis conforme seus interesses. Além disso, quando as corporações se envolvem em práticas moralmente inaceitáveis, mas não condenáveis pela ausência de leis, novas leis e regulamentações podem surgir para evitar sua reincidência (DABOUD et al, 1985).

De qualquer forma, os dois quesitos necessários para definir a criminalidade são que o ato deve ser socialmente prejudicial e que deve haver disposições legais para penalização do ato (SUTHERLAND, 1945); podendo o crime corporativo se constituir também em uma omissão ou comissão, que decorra ainda de uma decisão ou negligência, dolosa ou culposa, tomada por elementos da estrutura organizacional, conforme os 
objetivos da corporação, com seus procedimentos operacionais ou estratégicos ou, ainda, com o caldeirão cultural da organização, fortemente influenciados pela busca do lucro e por benefícios exclusivos à empresa (PAYNE, 2012; CLINARD; YEAGER, 2006; TOMASIC, 1993, KRAMER, 1984).

Os embates teóricos entre o crime corporativo formal e a materialidade dos prejuízos sociais da conduta corporativa permanecem vivos (TOMBS, 2009), porém é importante reconhecer as implicações dessa distinção (corporate crime versus social harm) (TOMBS, 2004). A lógica corporativa, que coloca o lucro acima da vida, pode ser explicada pelo alto poder e influência das corporações na elaboração e aplicação das leis, evitando que esses acontecimentos sejam nominados como crimes (MICHALOWSKI; KRAMER,1987; PEARCE; TOMBS, 1999). Quando Sutherland (1945) iniciou os estudos sobre crimes corporativos, o autor ressaltou a pouca importância a eles atribuídos, ao contrário do que acontece com os crimes de rua que, potencialmente, incorrem em menores prejuízos.

Vale ressaltar que o crime corporativo tende a beneficiar a corporação ou seus funcionários (PAYNE, 2012) e que pode ser definido com um subconjunto de crimes de colarinho branco (TOMASIC, 1993; PAYNE, 2012), que não causam danos físicos imediatos, aparentemente sem violência e intangíveis, e podem ser recorrentes e se estender no tempo, sendo difícil precisar seu ponto inicial (GREEN, 2007). Esses crimes podem ser violações administrativas, ambientais, financeiras, trabalhistas, operacionais ou comerciais, frequentemente por elementos do topo da hierarquia (CLINARD; YEAGER, 2006; e SUTHERLAND, 1945), de extratos sociais privilegiados, resultando não em ação criminal, mas em ações indenizatórias, com sanções na forma de avisos, ordens para cessar e desistir ou, eventualmente, na perda de uma licença (COLEMAN, 2005).

A mídia expõe com frequência escândalos que envolvem crimes corporativos, mas, por vezes, dão espaço a discursos ideológicos que isentam os suspeitos diretos, mitigam suas responsabilidades ou as transferem para terceiros (OLIVEIRA; VALADÃO JÚNIOR; MIRANDA, 2013). Assim, as corporações terminam isentas de culpa, plena ou parcial, sem assumirem os reais custos de seus comportamentos ilícitos e custos sociais e ambientais são arcados indevidamente pela sociedade (BORGES et al, 2016).

\section{Procedimentos Metodológicos}

O método implica na observação e análise sistemática de fenômenos reais por meio de passos sucessivos, embasados em conhecimentos teóricos, cujo intuito é atingir determinados objetivos para explicar determinados fenômenos (GOLDENBERG, 1997). Partiu-se de uma escolha qualitativa para o estudo.

Foram observados elementos de pesquisa descritiva, exigindo informações sobre o objeto de estudo, a fim de descrever e caracterizar os acontecimentos de uma dada realidade (o acontecimento em Bento Rodrigues) (TRIVIÑOS,1987). Quanto aos procedimentos, observaram-se as orientações para pesquisa documental, próxima à pesquisa bibliográfica (FONSECA, 2002).

As reportagens foram pesquisadas e selecionadas para a análise de discurso. A opção pelas revistas Carta Capital e Veja foi baseada em seu alcance, sendo identificadas entre os semanais mais influentes no Brasil (O GRITO, 2008; MORAES, 2015), além de terem alinhamentos ideológicos e perfis de leitores distintos, porém complementares (MORAES, 2015). Foram escolhidas treze reportagens (Quadro 1) entre suas publicações impressas e on-line e entre 05/11/15 e 05/11/16, i.e., até um ano do fato gerador do crime corporativo ambiental. Na seleção foram utilizados os seguintes critérios: 1) publicações disponíveis online ou em versão impressa, no período; 2) reportagens completas e que se referissem ao rompimento da barragem de Fundão, em Bento Rodrigues; 3) uso da junção de palavras "Bento Rodrigues", nas buscas eletrônicas, a fim de encontrar as reportagens sobre o caso a ser analisado. Esse critério foi adotado pelo fato de outros subdistritos atingidos, como Paracatu de Baixo e Camargos, não terem sido referências na publicização do caso. Nas reportagens on-line, foram considerados apenas os elementos textuais-verbais, sendo desconsiderados os eventuais vídeos e fotos nelas inseridos. 


\section{Quadro 1 - Corpus de pesquisa}

\section{CARTA CAPITAL}

1. Coisas \#15: especial desastre ambiental em Bento Rodrigues; 13 de novembro de 2015, Disponível em: <http://justificando.cartacapital.com.br/2015/11/13/coisas-15-especial-desastre-ambiental-em-bentorodrigues/>. Acesso em: 15 de abr. 2017.

2. Desastre de Mariana afetou mais de 660 quilômetros de rios; 06 de janeiro de 2016. Disponível em: <https:// www.cartacapital.com.br/sustentabilidade/desastre-de-mariana-afetou-mais-de-660-quilometros-de-rios. 2 Acesso em: 15 de abr. 2017.

3. Mar de lama, literalmente; 15 de novembro de 2015. Disponível em: <https://www.cartacapital.com.br/ revista/876/mar-de-lama-literalmente-6686.html>. Acesso em: 15 de abr. 2017.

4. Mariana, desastre que nada ensinou; 1 de dezembro de 2015. Disponível em: <https://www.cartacapital. com.br/revista/878/quem-brinca-com-lama-5910.html>. Acesso em: 15 de abr. 2017.

5. Mariana: desastres viram chance de ganhar dinheiro sobre o sofrimento; 12 de novembro de 2015. Disponível em: <https://www.cartacapital.com.br/sociedade/mariana-desastres-viram-chance-de-ganhar-dinheiro-sobreo-sofrimento-5488.html>. Acesso em: 15 de abr. 2017.

6. Mariana: essa não é uma tragédia ambiental; 8 de novembro de 2015. Disponível em: <https://www. cartacapital.com.br/sustentabilidade/essa-nao-e-uma-tragedia-ambiental-1258.html>. Acesso em: $15 \mathrm{de}$ abr. 2017.

7. Pesquisa revela dano à imagem da Samarco; 28 de junho de 2016. Disponível em: <https://www.cartacapital. com.br/sociedade/samarco-a-empresa-que-mais-causa-danos-ambientais-no-brasil>. Acesso em: 15 de abr. 2017.

8. Tragédia de Mariana: MPF denuncia 21 pessoas por homicídio doloso; 20 de outubro de 2016. Disponível em: <https://www.cartacapital.com.br/politica/tragedia-de-mariana-mpf-denuncia-21-pessoas-por-homicidiodoloso>. Acesso em: 15 de abr. 2017.

\section{REVISTA VEJA}

1. Tragédia de Mariana, novembro de 2015. Disponível em: <http://veja.abril.com.br/complemento/brasil/paraque-nao-se-repita/>. Acesso em: 15 de abr. 2017.

2. No rastro da tragédia: um ano depois; novembro de 2016. Disponível em: <http://veja.abril.com.br/ complemento/brasil/no-rastro-da-tragedia/>. Acesso em: 15 de abr. 2017.

3. Mineradoras cogitaram evacuar Bento Rodrigues em 2012, aponta PF; 22 de junho de 2016. Disponível em: $<\mathrm{http}$ ://veja.abril.com.br/brasil/mineradoras-cogitaram-evacuar-bento-rodrigues-em-2012-aponta-pf/>. Acesso em: 15 de abr. 2017.

4. Tragédia de Mariana: lama que arrasou rios ameaça o ecossistema marinho; 20 de novembro de 2015.

Disponível em: <http://veja.abril.com.br/brasil/tragedia-de-mariana-lama-que-arrasou-rios-ameaca-oecossistema-marinho/>. Acesso em: 15 de abr. 2017.

Tragédia em Mariana: barragem de Fundão tinha lama da Vale; 24 de novembro de 2015. Disponível

Em seguida, realizou-se uma análise de discurso, a fim de identificar elementos discursivos que relacionassem com o acontecimento de Bento Rodrigues e com a discussão teórica acima, validando suas argumentações. A análise do discurso foi efetuada segundo um conjunto de técnicas de análise dos textos, procedimentos sistemáticos e objetivos de descrição do conteúdo das mensagens, a fim de identificar indicadores que possibilitassem inferir conhecimentos com respeito às condições de produção e recepção dessas mensagens (BARDIN, 2006), a partir de duas perspectivas: lexical e de elementos textuais, intertextuais e ideológicos de construção do discurso, categorizados em função de estruturas, proposições, representações e léxico, em especial com base em Fairclough (1993 e 1995).

\section{Análise do discurso e resultados}

Nesta seção, são apresentados os resultados da pesquisa em duas partes: (1) a análise lexical e (2) a análise de elementos na construção do discurso. Foram analisadas as ocorrências de sentenças, de figuras de linguagem, de proposições e de vocabulário que expressassem alguma forma de intenção ou de percepção involuntária sobre a identidade corporativa ou imagem das três empresas envolvidas no crime, Samarco, Vale e BHP, e seus atos, segundo cinco critérios estabelecidos. 


\section{Análise lexical}

Computaram-se as ocorrências de expressões que poderiam denotar algum juízo de valor, dos jornalistas ou da linha editorial das revistas, em relação à intencionalidade e gravidade do evento. As expressões mais recorrentes foram: "tragédia", "vítima", "culpada ou culpa", "desastre", "acidente", "crime", "catástrofe”, "denúncia ou denunciada" (Quadro 2).

Quadro 2: Termos recorrentes relacionados à identificação do ocorrido

\begin{tabular}{|c|c|l|}
\hline TERMO & $\mathrm{f}(\mathrm{x})$ & Obs.: \\
\hline "tragédia" & 46 & \\
\hline "vítima" & 9 & \\
\hline "culpad" ou "culpa" & 5 & \\
\hline "desastre" & 21 & \\
\hline "acidente" & 5 & Veja: 4 (3 citações indiretas de autoridades ou da empresa). \\
\hline "crime" & 5 & \\
\hline "catástrofe" & 3 & \\
\hline "denúncia" ou "denunciad" & 3 & Todos em matéria da Veja. \\
\hline
\end{tabular}

Embora haja claras limitações sobre esse tipo de contagem, a análise lexical aponta que há uma clara opção, em ambos os veículos, por uma postura crítica ao ocorrido, sem indicação concreta de uma postura ideologicamente enviesada. O discurso pode ser compreendido por meio do conjunto de estratégias para adequar a mensagem e suas possíveis significações a um posicionamento ideológico e teleológico (CHARAUDEAU, 2002). Nesse sentido, a opção por termos como "acidente", "desastre", "catástrofe" ou "tragédia" por si só não permitem indicar o reconhecimento de uma responsabilidade técnico-jurídica, nem isoladamente podem indicar uma tentativa de naturalização do ocorrido, isto é, de transferência de responsabilidades corporativas e legais para uma causa natural ou acidental. Entretanto, em conjunto, a análise lexical e dos elementos do discurso indica a prevalência, nos discursos, do reconhecimento de uma responsabilidade direta da empresa.

As palavras "vítima", "culpa" e "denúncia" tiveram presença irrelevante, indicando que o tratamento dado ao ocorrido não é de crime. Isto pode ser explicado por processos por danos civis, pois, de acordo com perspectivas legalistas (BAUCUS; DWORKIN, 1991), somente são considerados criminosos aqueles condenados pela justiça criminal. No entanto, a despeito das controvérsias sobre o que seja crime corporativo, sua definição deve levar em conta direitos humanos, individuais e coletivos, e os prejuízos sociais e materiais provocados na busca de maiores lucros.

\section{A análise de elementos na construção do discurso}

Nesta seção, discutimos as ocorrências de estruturas, proposições, representações e léxicos selecionados, segundo os critérios e significações indicados de cada um dos elementos na construção do discurso: hegemonia, contradição, reconhecimento, intertextualidade e representação.

Hegemonia (discurso e poder): esta categoria computa as ocorrências que refletem o poder econômico da empresa ou político-administrativo de órgãos ou representantes do governo. Entende-se como hegemonia a dominação baseada em alianças entre grupos distintos sobre os demais, e sua expressão de supremacia é refletida no discurso e em sua natureza teleológica, que tem por objetivo legitimar a relação de poder ou gerar consentimento (FAIRCLOUGH, 1993 e 1995). Por exemplo, o governo coloca a empresa como vítima: "Secretário de Estado de Minas Gerais diz que a Samarco é vítima de um rompimento..." (CARTA CAPITAL, 2015), defendendo a empresa: "Pimentel concedeu uma entrevista na sede da Samarco e seu Secretário de Desenvolvimento, Altamir Rôso, chegou a encampar a defesa da mineradora..." (CARTA CAPITAL, 2015). A Carta Capital caracteriza o acontecido como desastre natural e não provocado pela ação humana: “... imagens aéreas parecem sugerir um desastre natural de grandes proporções..." (CARTA CAPITAL, 2015);

Contradição (discurso e poder): computa as ocorrências que refletem desafios ao discurso e ideologia das forças hegemônicas. Hegemonia é vista como uma medida de poder em uma relação dialética, de 
mudança, radical ou progressiva. Assim, o discurso revela também forças sociais que se apresentam como via de mudança. Esse cenário é instável, na medida da estabilidade das alianças que lhe sustentam e do consentimento por elas obtido. Sem desconsiderar as dificuldades de mudança no contexto fragmentado da pós-modernidade,

reconhecem-se elementos de contraposição à hegemonia no discurso (FAIRCLOUG, 1993 e 1995), como quando a Carta Capital sugere que não é um desastre, existindo outras verdades: "... alguém tem que dizer algumas verdades sobre o “desastre”...” (CARTA CAPITAL, 2015) e “... licença ambiental não é salvo-conduto... nem significa legalidade. Uma barragem de rejeitos não se rompe por acaso..." (CARTA CAPITAL, 15); assume que é um crime sociológico e que sua responsabilidade se estende além da Samarco: "Pela lei brasileira, a priori, as responsabilidades desse crime socioecológico... recaem sobre a Vale e a BHP..." (CARTA CAPITAL, 2015). A Veja se apoia em especialistas para afirmar as consequências irreparáveis do crime: "Especialistas ouvidos pelo site de VEJA afirmam que os prejuízos ambientais da tragédia são 'irreparáveis'..." (VEJA, 20 de novembro de 2015).

Reconhecimento (discurso e agência): o sujeito e a transitividade no discurso implicam o questionamento sobre sujeito da ação e sobre sua relação de causalidade. A ação pode ter consequências sobre o próprio sujeito ou sobre terceiros, podendo ser diretas ou indiretas (FAIRCLOUG, 1993). Nesse sentido, o problema da agência, na relação corporativa, ganha evidência e pode ser identificado no discurso, quando ele reconhece vias pelas quais organizações e pessoas são afetadas (dos moradores de Bento Rodrigues aos acionistas da BHP em Sidnei), direta ou indiretamente, pelos atos da corporação; bem como quem são os reconhecidos sujeitos desses atos (de diretores e gerentes da Samarco à alta administração da VALE/BHP).

Por exemplo: “... de quem é a barragem? Da empresa Samarco... casamento entre a Vale... e a BHP..." (CARTA CAPITAL, 2015); “... dezenas de moradores e trabalhadores da mina acabaram soterrados..." (CARTA CAPITAL, 2015); "a catástrofe provocada pelas mineradoras Vale e BHP vai gerar muitos conflitos socioecológicos, longos no tempo e no espaço... conflitos em torno dos 'valores'..." (CARTA CAPITAL, 2015); “... accões da Vale despencaram 7,5\%, puxando a Bolsa de Valores de São Paulo para uma queda de 2,35\%. Na bolsa de Sidney, os papeis da BHP recuaram 2,5\%..." (VEJA, 2015).

Intertextualidade (discurso \& contexto): recurso linguístico que busca referências extratexto para apresentar informações ou representações que podem reiterar o posicionamento do produtor do discurso, buscar aprovação ou compartilhamento de seus destinatários ou, ainda, transferir para fora do discurso ou para outrem, de forma específica (e.g. citações diretas ou indiretas) ou de forma genérica (e.g. metáforas), a responsabilidade ou autoria de alguma conotação da mensagem (FAIRCLOUGH, 1993), reforçando elementos de hegemonia, contradição ou agência. Por exemplo: "Aécio Neves diz que... não é hora de apontar os culpados..." (CARTA CAPITAL, 2015); "a devastação é resultado da passagem de um tsunami..." (CARTA CAPITAL, 2015); "Rio Doce, convertido em abatedouro de seres aquáticos..." (CARTA CAPITAL, 2015); “... vampiros de desastres ecológicos..." (CARTA CAPITAL, 2015); “...executivos classificam o evento como o '11 de setembro'... (VEJA, 2015); "segundo... coordenador da... a terra ficou 'totalmente infértil'..." (VEJA, 2015).

Representação (discurso e construção da realidade): computa as ocorrências que refletem ou expressam posicionamentos, das revistas, de seus repórteres ou de suas linhas editoriais, reconhecendo a efetiva responsabilidade da empresa na tragédia e no crime. Por exemplo, a Carta Capital menciona (1) a transferência de responsabilidade da empresa quanto ao crime socioecológico, desconsiderando o conceito legalista do termo: "... A culpa da catástrofe, um crime socioecológico, tem sido... transferida para a natureza, enquanto as responsabilidades de empresas e governos são diluídas..." (CARTA CAPITAL, 2015); (2) a omissão ou negligência da empresa, que é um aspecto conceitual de crime corporativo: “... evidente que houve negligência..." (CARTA CAPITAL, 2016); bem como o fato de o crime ter ocorrido na busca dos objetivos de lucros: "... foco na redução dos custos e mensuração técnica e operacional da vulnerabilidade, mais do que em questões de cidadania..." (CARTA CAPITAL, 2015). A Veja, por seu turno, (1) culpa a mineradora pelo acontecido: “... todos os indícios levam à culpa da mineradora... (VEJA, 2016); “... não isenta a companhia da responsabilidade pelo o que aconteceu..." (VEJA, 2015); e, inclusive, (2) coloca a responsabilidade na empresa pela sua omissão: "mineradoras cogitaram evacuar Bento Rodrigues em 2012, aponta PF." (VEJA, 2016). 
A prevalência de ocorrências com significações condenatórias confirma a construção de uma representação de realidade negativa para a empresa e para sua administração e direção executiva. Seus stakeholders imediatos, a coletividade em geral e os moradores das áreas afetadas, desde Bento Rodrigues ao litoral capixaba, em especial, figuram como as vítimas do ocorrido. Há evidências de que, em curto prazo, o desempenho da Samarco/VALE/BHP tenha sido afetado e de que, em longo prazo, o mesmo ocorra com seu desempenho social.

$\mathrm{Na}$ análise da categoria hegemonia, a empresa, o Estado e políticos, de diferentes linhas partidárias, tentam amenizar o ocorrido. O capital e o Estado convergem para um discurso minimizador das consequências do crime corporativo cometido. Os dois veículos analisados relacionam o acontecimento a um crime - ambiental e social - e que se deve penalizar os culpados não somente financeiramente, visto que, independentemente do valor monetário a ser cobrado, os danos ocasionados não poderão ser revertidos. A existência de controvérsias dentro do governo, entre seus diferentes órgãos e entre pesquisadores e institutos, reafirma a natureza parcialmente política da tragédia (crime corporativo), implicando a necessidade de negociação e comunicação, entre diversos setores da sociedade, nas esferas política, social, econômica e legal.

As reportagens confirmam, em seus discursos, a ambiguidade entre a qualificação do ocorrido como desastre ou crime. Apesar dos cuidados das revistas em evitar um posicionamento categórico, fica evidente o retrato negativo deixado pelas reportagens sobre as empresas, sobre órgãos governamentais e sobre políticos de expressão nacional. Não obstante a dificuldade de caracterizar o crime corporativo formal, os prejuízos sociais, ambientais e econômicos, para diferentes parcelas da sociedade (local, regional e nacional), tornam-se evidentes (i.e., o embate entre corporate crime e social harm, como já discutido). Ainda, a relação entre GC, RSC, sustentabilidade, teoria do stakeholder e desempenho (social e econômico) possivelmente será afetada negativamente, pois, como também já discutido, ela depende das representações que surgem em discursos sociais sobre a firma, afetando sua imagem corporativa, seu simbolismo organizacional e sua identidade e identificação organizacional (NIELSEN; JOHANSEN, 2010, e HE; BROWN, 2003).

\section{Considerações finais}

O objetivo desta pesquisa foi analisar as representações de um crime corporativo em duas revistas de circulação nacional: Veja e Carta Capital.

A pesquisa tem implicações teóricas e práticas. Quanto às práticas, os resultados mostraram que, primeiramente, a Samarco/VALE/BHP, apesar da hegemonia histórica da associação do capital com o Estado (BRAUDEL, 1977), não logrou escapar de um retrato negativo nas reportagens dos dois veículos analisados. De fato, as reportagens da Carta Capital foram mais agudas na contradição dessa hegemonia. Contudo ambas as revistas foram unânimes em questionar a responsabilidade social da empresa, deixando um retrato deveras negativo dela. Por fim, provavelmente, o indicador mais relevante para esta discussão foi que ambos os veículos enumeraram diferentes interesses, grupos sociais e aspectos ambientais, como as vítimas dos prejuízos decorrentes diretamente do evento. Nesse aspecto, a análise de discurso efetuada consolida a percepção de que, hoje, não mais se pode avaliar o desempenho de uma empresa sem levar em conta os efeitos de sua atividade sobre a sociedade e seu meio, tampouco ignorar as responsabilidades que cabem à corporação nesse sentido.

Os aspectos sociológicos e as dimensões não econômicas da responsabilidade social e sustentabilidade representam perdas para stakeholders que não podem ser monetariamente contabilizadas. Representam perdas de direitos e redução de qualidade de vida, enquanto que, para a empresa, tudo se limita a uma questão econômica. Os danos humanos, sociais e ambientais causados pelo evento, em Bento Rodrigues, nos estados de Minas Gerais e Espírito Santo, e no litoral brasileiro, são imensuráveis.

Quanto às implicações teóricas, após a análise do referencial teórico, do evento e dos discursos sobre este, é possível argumentar que o evento caracteriza-se como um crime corporativo, indicando a necessidades de novos referenciais teóricos para o estudo das organizações. Ainda que as pertinentes considerações jurídicas não façam parte do escopo do deste trabalho, há considerações relevantes que permitem interpretar o ocorrido como um crime corporativo. Houve claro desrespeito a práticas e condutas 
reconhecidas como desejáveis no arcabouço teórico e empírico dos estudos organizacionais. Pilares, bases e linhas fundamentais deixaram de ser observadas. As maiores vítimas desse crime foram seres humanos, em especial: os moradores de Bento Rodrigues; acionistas de diversos tamanhos da VALE e da BHP; funcionários da Samarco; parceiros da Samarco; o meio ambiente, um bem público e coletivo; as economias de inúmeros comunidades pelas quais a lama passou rio abaixo; e por fim, não menos importante, a sociedade e o Estado, fiéis depositários do bem comum.

Esta pesquisa estimula uma agenda rica para ampliar os estudos sobre as organizações e suas relações com a sociedade e o governo. Como sugestão para futuros estudos, indicamos a realização de pesquisas que analisem as relações e conexões entre empresas envolvidas em práticas criminosas e os governos, a partir de seus representantes.

\section{Referências}

ALMEIDA, F. O bom negócio da sustentabilidade. Rio de Janeiro: Nova Fronteira, 2002.

AMARANTE, J. G. M. C. C. et al. Governança corporativa e responsabilidade social corporativa: uma revisão sistemática dessa relação. Revista de Ciências da Administração, Florianópolis, v. 17, n. 43, p. 123-140, 2015.

ARGANDOÑA, A. The stakeholder theory and the common good. Journal of Business Ethics, [S.I.], v. 17, n. 9, p. 1093-1102, 1998.

BARDIN, L. Análise de conteúdo. Lisboa: Edições 70, 2006.

BAUCUS, M. S; DWORKIN, T. M. What is corporate crime? It is not illegal corporate behavior. Law \& Policy, [S.I.], v. 13, n. 3, p. 231-244, 1991.

BENITES, L. L.; POLO, E. F. A sustentabilidade como ferramenta estratégica empresarial: governança corporativa e aplicação do triple bottom line na Masisa. Revista Administração, Santa Maria, v. 6, n. esp, p. 827-841, 2013.

BESSIRE, D. et al. What is "good" Corporate Governance? In: ARAS, G.; CROWTHER, D. (org.). A handbook of corporate governance and corporate social responsibility. Abingdon: Routledge, 2010. p. 37-51.

BOBBIO, N. Teoria geral do estado.32. ed. São Paulo: Elsevier, 2000.

BOFF, L. O pecado maior do capitalismo: o risco do ecocídio e do biocídio. [S.I.:s.n.], 2010. Disponível em: http://www.leonardoboff.com/site/lboff.htm. Acesso em: 02 dez. 2016.

BORCHARDT, M. A.; SIENA, O. Discurso organizacional sobre sustentabilidade no contexto do complexo hidrelétrico do Rio Madeira. In: ENCONTRO INTERNACIONAL SOBRE GESTÃO EMPRESARIAL E MEIO AMBIENTE, 14., São Paulo. Anais [...]. São Paulo: [s.n.], 2014.

BORGES, S. R. P. et al. A opinião pública sobre crimes corporativos: O que pensam os estudantes de cursos de graduação da área de negócios. Administração: ensino e pesquisa, Rio de Janeiro, v. 17, n. 1, p. 33-72, 2016.

BORGES, S. R. P.; MEDEIROS, C. R. de O. Crimes corporativos no Brasil: uma análise de grandes empresas no estado de Minas Gerais. Revista Ciências Administrativas, Fortaleza, v. 20, n. 2, p. $452-$ 479, jul./dez. 2014.

BRASIL. Supremo Tribunal Federal (1. Turma). Recurso Extraordinário n. 548181.Direito penal. Crime ambiental. Responsabilidade penal da pessoa jurídica. Condicionamento da ação penal à identificação e à persecução concomitante da pessoa física que não encontra amparo na constituição da república. Recorrente: Ministério Publico Federal. Recorrido: Petróleo Brasileiro S.A - PETROBRÁS. Relatora: Min. Rosa Weber, 30 de outubro de 2014. Disponível em: http://www.stf.jus.br/portal/jurisprudencia/ listarJurisprudencia.asp?s1=\%28548181\%2ENUME $\% 2 \mathrm{E}+\mathrm{OU}+548181 \% 2 \mathrm{EACMS} \% 2 \mathrm{E} \% 29 \&$ base $=$ baseA cordaos\&url=http://tinyurl.com/z5eg53e. Acesso em: 29 abr. 2017. 
BRAUDEL, F. Afterthoughts on material civilization and capitalism. Baltimore: John Hopkins University Press, 1977.

CANTO, R. Mariana: essa não é uma tragédia ambiental. Carta Capital, [S.I.], 8 nov. 2015. Disponível em: https://www.cartacapital.com.br/sustentabilidade/essa-nao-e-uma-tragedia-ambiental-1258.html. Acesso em: 15 de abr. 2017.

RODRIGUES, L. Tragédia de Mariana: MPF denuncia 21 pessoas por homicídio doloso. Carta Capital, [S.I.], 20 out. 2016. Disponível em: https://www.cartacapital.com.br/politica/tragedia-de-mariana-mpfdenuncia-21-pessoas-por-homicidio-doloso. Acesso em: 15 de abr. 2017.

COISAS \#15: especial desastre ambiental em Bento Rodrigues. Carta Capital, [S.I.], 13 nov. 2015, Disponível em: http://justificando.cartacapital.com.br/2015/11/13/coisas-15-especial-desastre-ambientalem-bento-rodrigues/. Acesso em: 15 abr. 2017.

MAR de lama, literalmente.Carta Capital, [S.I.], 15 nov. 2015. Disponível em: https://www.cartacapital. com.br/revista/876/mar-de-lama-literalmente-6686.html. Acesso em: 15 abr. 2017.

MARIANA, desastre que nada ensinou. Carta Capital, [S.I.],1 dez. 2015a. Disponível em: https://www. cartacapital.com.br/revista/878/quem-brinca-com-lama-5910.html. Acesso em: 15 abr. 2017.

MARIANA: desastres viram chance de ganhar dinheiro sobre o sofrimento. Carta Capital, [S.I.], 12 nov. 2015b. Disponível em: https://www.cartacapital.com.br/sociedade/mariana-desastres-viram-chance-deganhar-dinheiro-sobre-o-sofrimento-5488.html. Acesso em: 15 abr. 2017.

PESQUISA revela dano à imagem da Samarco. Carta Capital, [S.I.], 28 jun. 2016. Disponível em: https:// www.cartacapital.com.br/sociedade/samarco-a-empresa-que-mais-causa-danos-ambientais-no-brasil. Acesso em: 15 de abr. 2017.

DESASTRE de Mariana afetou mais de 660 quilômetros de rios. Carta Capital, [S.I.], 06 jan. 2016. Disponível em: https://www.cartacapital.com.br/sustentabilidade/desastre-de-mariana-afetou-mais-de660-quilometros-de-rios. Acesso em: 15 de abr. 2017.

CHARAUDEAU, P. A communicative conception of discourse. Discourse Studies, [S.I.], v. 4, n. 3, p.301318, ago. 2002.

CLARO; P. B. O.; CLARO, D. P.; AMÂNCIO, R. Entendendo o conceito de Sustentabilidade nas organizações. Revista Administração, São Paulo, v. 43, n. 4, p. 289-300, out./dez. 2008.

CLINARD. M. B.; YEAGER, P. C. Corporate crime. New Brunswick: Transaction Publisher, 2006.

COELHO, A. L. A.; COELHO, C.; GODOI, C. K. O discurso da sustentabilidade e sua inserção no contexto organizacional. Revista Gestão \& Conexões, Vitória, v. 2, n.1, p. 147-186, 2013.

COLEMAN, J. W. A elite do crime: para entender o crime do colarinho branco. 5. ed. São Paulo: Manole, 2005.

COSTA, S. R.; VALDISSER, C. R. Uma análise do discurso organizacional sob o prisma da responsabilidade socioambiental: o caso SABESP. Revista Metropolitana de Sustentabilidade, São Paulo, v. 5, n.1, p. 78-97, 2015.

SILVA, S. S. da; REIS, R. P. Sustentabilidade nos discursos organizacionais: uma luz no fim do túnel ou perfumaria? In:ENCONTRO DAASSOCIAÇÃO NACIONAL DE PÓS-GRADUAÇÃO E PESQUISA EM ADMINISTRAÇÃO, 35., 2011, Rio de Janeiro. Anais [...]. Rio de Janeiro: Anpad, 2011.

SILVA, S. S. da; REIS, R. P.; AMÂNCIO, R. Conceitos atribuídos à sustentabilidade em organizações de diferentes setores. Revista de Ciências da Administração, Florianópolis, v. 16, n. 40, p. 90-103, 2014. SILVA, S. S. da; SANTINELLI, F.; SILVA, J. P. B. da.Sustentabilidade nas empresas públicas de Minas Gerais: um estudo multicasos. Gestão e Sociedade, Belo Horizonte, v. 8, n.21, p. 795-809, 2014.

DELMANTO, C. Código penal comentado. 5. ed. São Paulo: Renovar, 2000. 
DINIZ, M. H. Curso de direito civil brasileiro: teoria geral do direito civil. 29. ed. São Paulo: Saraiva, 2012.

DONALDSON, J.; FAFALIOU, I. Business ethics, corporate social responsibility and Corporate Governance: a review and summary critique. European Research Studies, [S.I.],v. VI, n. 1-2, p. 90-109, 2003.

ELKINGTON, J. Cannibals with forks: triple bottom line of 21st century business. Stoney Creek, CT: New Society Publishers, 1997.

ELKINGTON, J. Enter the triple bottom line. [S.I.: s.n.], 2004. Disponível em: http://www.johnelkington. com/archive/TBL-elkington-chapter.pdf. Acesso em: 10 dez. 2016.

ESTEFAM, A.; GONÇALVES, V. E. R. Direito penal esquematizado: parte geral. São Paulo: Saraiva, 2012.

FAIRCLOUGH, N. Discourse and social change. Cambridge: Polity, 1993.

FAIRCLOUGH, N.Critical discourse analysis: the critical study of language. Harlow: Longman, 1995.

FLANNERY, D. Understanding different interpretations of corporate social responsibility in the United States. In: RYAN, L. V.; GASPARSKI, W. W. (org.). Business students focus on ethics. Londres: Transaction Press, 2000. cap. 6.

FONSECA, J. J. S. Metodologia da pesquisa científica. Fortaleza: UECE, 2002. 1 Apostila.

FREITAS, M. et al. O desastre da Samarco/VALE/BHP: análise crítica de alguns discursos, racionalidades e percepções. Ciência e Cultura, São Paulo, v. 68, n. 3, p. 51-56, set. 2016.

FRIEDMAN, M. Capitalism and freedom. Chicago: University of Chicago Press, 1962.

GREEN, P. S. A normative approach to white-collar crime. In: PONTELL, H. N.; GEIS, G. International handbook of white-collar and corporate crime. New York: Springer, 2007. p.223-247.

HALPERN, B. S. et al. Achieving the triple bottom line in the face of inherent trade-offs among social equity, economic return, and conservation. Proceedings of the National Academy of Sciences of the United States of America, [S.I.], v. 110, n. 15, p. 6229-6234, 2013.

HE, H.; BROWN, A. D. Organizational identity and organizational identification: a review of the literature and suggestions for future research. Group \& Organizational Management, [S.I.], v. 38, n. 1, p. 3-35, 2003.

HELMIG, B.; SPRAUL, K.; INGENHOFF, D. Under positive pressure: how stakeholder pressure affects corporate social responsibility implementation. Business \& Society, [S.I.], v. 55, n. 2, p. 151-187, 2016.

HENRIQUES, M. S.; SANT'ANA, L. F. Ideias-força evidenciadas no discurso organizacional sobre sustentabilidade. Revista Organicom, São Paulo, v. 10, n. 18, p. 71-82, 2013.

JO, H.; HARJOTO, M. A. The causal effect of corporate governance on corporate social responsibility. Journal of Business Ethics, [S.I.], v. 106, n. 1, p. 53-72, 2012.

KELSEN, H. Teoria pura do Direito. 6. ed. São Paulo: Martins Fontes, 1998.

MACHADO, L. A. Direito criminal: parte geral. São Paulo: Ed. Revista dos Tribunais, 1987.

MAGILL, M.; QUINZII, M.; ROCHET, J. C. A theory of the stakeholder corporation. Econometrica, [S.I.], v. 83 , n. 5 , p. $1685-1725$, set. 2015.

MICHALOWSKI, R. J.; KRAMER, R. C. The space between laws: the problem of corporate crime in a transnational context. Social Problems, [S.I.],v. 34, n. 1, p.34-53, 1987.

MIRABETE, J. F. Código penal interpretado. São Paulo: Atlas, 2000.

MORAES, C. H. Entre o clima e a economia: enquadramentos discursivos sobre a Rio+20 nas 
revistas Veja, Isto É, Época e Carta Capital. 2015. Tese (Doutorado em Comunicação e Informação) Universidade Federal Rio Grande do Sul, Porto Alegre, 2015.

NIELSEN, A. E.; JOHANSEN, T. S. Corporate social responsibility and corporate identity: potentials for disciplinary cross-fertilization within research and teaching. In: PODNAR, K.; BALMER, J. (org.). Contemplating the Corporate Marketing, Indentity \& Communication. Abingdon: Routledge, 2010. NTIM, C. G.; SOOBAROYEN, T. Corporate governance and performance in socially responsible corporations: new empirical insights from a neo-institutional framework. Corporate Governance: an International Review, [S.I.], v. 21, n. 5, p. 468-494, 2013.

DAS BANCAS: as 10 revistas mais influentes do Brasil. Revista O Grito, Recife, 27 out. 2008. Disponível em: http://revistaogrito.com/page/blog/2008/10/27/dasbancas-as-10-revistas-mais-influentesdo-brasil. Acesso em: 23 abr. 2017.

OLIVEIRA, C. R. de. Crimes corporativos e estudos organizacionais: uma aproximação possível e necessária. Revista de Administração de Empresas, São Paulo, v. 55, n. 2, p. 202-208, 2015.

OLIVEIRA, C. R. de.; VALADÃO-JUNIOR, V. M.; MIRANDA, R. Culpada ou inocente? Comentários de internautas sobre crimes corporativos. Revista de Administração de Empresas, São Paulo, v. 53, n. 6 , p. 617-628, nov./dez. 2013.

PAYNE, B. K. White-collar crime: the essentials. Thousand Oaks: Sage, 2012.

PEARCE, F.; TOMBS, S. Toxic Capitalism: corporate crime and the chemical industry. Toronto: Canadian Scholars' Press, 1999.

PHILIPPI, L. S. A construção do desenvolvimento sustentável. In: LEITE, A. L. T. A. Educação

Ambiental (curso básico à distância): questões ambientais: conceitos, história, problemas e alternativa. 2. ed. Brasília: Ministério do Meio Ambiente, 2001. v. 5.

SACHS, I. Desenvolvimento mundial: uma ideia sobre o desenvolvimento populacional. Revista Internacional dos Serviços Sociais, [S.I.], n. 141, 1994.

SAMARCO. Relatório da Administração e Demonstrações Financeiras: 2014. Belo Horizonte: SAMARCO, 2014. Disponível em: http://www.samarco.com/wp-content/uploads/2015/11/Relatorio-daAdministra-o-e-Demonstra-es-Financeiras-20141.pdf. Acesso em: 15 abr. 2017.

SILVA, D. C. et al. Isomorfismo e responsabilidade social corporativa das empresas que compõem o índice de sustentabilidade da BM\&FBovespa. Revista Ibero-Americana de Estratégia, São Paulo, v. 17, n. 3, p. 116-127, 2018.

SLAPER, T. F.; HALL, T. J. The triple bottom line: what is it and how does it work? Indiana Business Review, [S.I.], p. 4-8, Spring, 2011.

SUTHERLAND, E. Is "white collar crime" crime? American Sociological Review, [S.I.], v. 10, n. 2, p. 132-139, abr. 1945.

TEIXEIRA, A. V. Ativismo judicial: nos limites entre racionalidade jurídica e decisão política. Revista Direito GV, São Paulo, v. 8, n. 1, p. 37-58, jan./jun. 2012.

TOMASIC, R. Corporate crime and corporations law enforcement strategies in Australia. Camberra: University of Camberra, 1993. Discussion paper1/93. Disponível em: http://crg.aic.gov.au/reports/2-91. pdf. Acesso em: 23 abr. 2017.

TOMBS, S. Croportate crime. In: HALE, C. et al. Criminology. Oxford: OUP, 2009. p. 227-246.

TOMBS, S.; HILLYARD, P. Towards a political economy of harm: states, corporations and the production of inequality. In: HILLYARD, P. et al (org.). Beyond Criminology: taking harm seriously. Londres: Pluto Press, 2004. p. 30-54.

VALE S/A. Relatório de Sustentabilidade, 2014. [S.I.: s.n.], 2014. Disponível em: http://www.vale.com/ 
pt/aboutvale/sustainability/links/linksdownloadsdocuments/relatorio-de-sustentabilidade-2014.pdf. Acesso em: 23 dez. 2016.

VALE S/A. Relatório de Sustentabilidade, 2015. [S.I.: s.n.], 2015. Disponível em: http://www.vale.com/ PT/aboutvale/sustainability/links/LinksDownloadsDocuments/relatorio-de-sustentabilidade-2015.pdf. Acesso em: 23 dez. 2016.

VARELA, J. A.; ANTÓNIO, N. O bem comum e a teoria dos stakeholders. Lisboa: ISCTE-IUL: Business Research Unit, 2012. (Working Papers Series, 2).

PARA que não se repita. Veja, [S.I.], nov. 2015. Disponível em: http://veja.abril.com.br/complemento/ brasil/para-que-nao-se-repital. Acesso em: 15 abr. 2017.

FUSCO, N.Tragédia de Mariana: lama que arrasou rios ameaça o ecossistema marinho. Veja,[S.I.], 20 nov. 2015. Disponível em: http://veja.abril.com.br/brasil/tragedia-de-mariana-lama-que-arrasou-riosameaca-o-ecossistema-marinho/. Acesso em: 15 abr. 2017.

TRAGÉDIA em Mariana: barragem de fundão tinha lama da Vale. Veja, [S.I.], 24 nov. 2015. Disponível em: http://veja.abril.com.br/brasil/tragedia-em-mariana-barragem-de-fundao-tinha-lama-da-vale/. Acesso em: 15 abr. 2017.

MINERADORAS cogitaram evacuar Bento Rodrigues em 2012, aponta PF. Veja, [S.I.], 22 jun. 2016. Disponível em: http://veja.abril.com.br/brasil/mineradoras-cogitaram-evacuar-bento-rodrigues-em-2012aponta-pf/. Acesso em: 15 abr. 2017.

THOMAS, J. A.; RORIZ, J.; OLIVEIRA, X. No rastro da tragédia: um ano depois. Veja, [S.I.], nov 2016. Disponível em: http://veja.abril.com.br/complemento/brasil/no-rastro-da-tragedia/. Acesso em: 15 abr. 2017.

WEI, Y. C.; EGRI, C. P.; LIN, C. Y. Y. Do corporate social responsibility practices yield different business benefits in eastern and western contexts? Chinese Management Studies, [S.I.], v. 8, p. 556-576, 2014.

Submetido em: $14 / 04 / 2019$

Aprovado em: 24/04/2019 